\title{
Aortic Augmentation Index at 75bpm
}

National Cancer Institute

\section{Source}

National Cancer Institute. Aortic Augmentation Index at 75bpm. NCI Thesaurus. Code C122083.

The normalization of aortic augmentation index for heart rate, using a standard rate of seventy five beats per minute. 